\title{
P-6
}

\section{Fractionation of Heavy Metals by BCR Sequential Extraction in Coastal Marine Sediments around Colombo Harbour}

\author{
Gurusinghe V.N.* and Karunarathne P.K.D.M.C.
}

\author{
Department of Chemistry, Faculty of Applied Sciences, University of Sri Jayewardenepura, \\ Nugegoda, Sri Lanka \\ *varuni_ng@yahoo.com
}

\begin{abstract}
Marine environment around the Colombo harbour is prone to heavy coastal marine pollution due to heavy ship traffic, spilled oils, maintenance and repair of ships. Land based marine pollution is prominent near the coast of Kelani river estuary due to the fact that the river carries land run-offs, urban and domestic debris, industrial effluents, and agricultural wastes dumped directly into it. Lead $(\mathrm{Pb})$, chromium $(\mathrm{Cr})$, nickel $(\mathrm{Ni})$, copper $(\mathrm{Cu})$ and zinc $(\mathrm{Zn})$ are some of the heavy metals that have a tendency to accumulate in food chains originate from the sea. However, the heavy metal should be present in bioavailable forms to be entered in to biological systems. Thus the fractionation of heavy metals into four fractions (water and acid soluble, reducible, oxidisable, and residual) by the modified BCR (European Community Bureau of Reference) sequential extraction procedure prior to the analysis is a better way of interpreting heavy metal pollution in marine sediments.
\end{abstract}

In this study, field sampling was carried out twice in six locations adjacent to Colombo port in October 2011 (batch 1) and in March 2012 (batch 2) at the depth of 9-20 m depending on the location and the season. Metal fractionation was done according to modified BCR procedure and five elements $(\mathrm{Pb}, \mathrm{Cr}, \mathrm{Ni}, \mathrm{Cu}$, and $\mathrm{Zn})$ were analysed by flame atomic absorption spectroscopy (FAAS).

The sum of three steps of BCR and residue analysis were in good agreement with the total metal content obtained by aqua regia digestion followed by the FAAS analysis via standard addition method. The results showed that the levels of heavy metals vary widely by metal, by sampling site as well as by batch. Obtained results were compared with U.S.EPA-Region V, sediment quality criteria for concentration limits of heavy metal contaminants in sediments. The total metal contents in sediments of all metals except for $\mathrm{Pb}$ were above moderately polluted or polluted levels. More than $50 \%$ of total $\mathrm{Cu}$ and $\mathrm{Cr}$ contents were in residual and oxidisable fractions. Distribution of $\mathrm{Ni}$ and $\mathrm{Zn}$ did not have a clear pattern. Bioavailable metal contents of all five metals under investigation were below the risk levels provided by US EPA sediment quality criteria, except for $\mathrm{Ni}$ in one location and $\mathrm{Zn}$ in two locations.

Keywords: Marine sediments, BCR Sequential extraction, Heavy metals, AAS

Proceedings of the International Forestry and Environment Symposium 2013 of the Department of Forestry and Environmental Science, University of Sri Jayewardenepura, Sri Lanka. 